1 Supplementary Materials for:

\title{
2 A cell-cell communication-based screening system 3 for novel microbes with target enzyme activities
}

4

5 Haseong Kim ${ }^{1}$, Eugene Rha ${ }^{1}$, Wonjae Seong ${ }^{1,2}$, Soo-Jin Yeom ${ }^{1}$, Dae-Hee 6 Lee $^{1,2}$, and Seung-Goo Lee ${ }^{1,2}$

7
1) Synthetic Biology \& Bioengineering Research Center, Korea Research Institute of Bioscience and Biotechnology, 125 Gwahak-ro, Yuseong-gu, Daejeon, South Korea

2) Biosystems and Bioengineering Program, University of Science and Technology, 217 Gajung-ro, Yuseong-gu, Daejeon, South Korea

Corresponding Author:

E-mail: sglee@kribb.re.kr

The file include:

Fig. S1. Vector maps for MP-GESS construction and evaluation.

Fig. S2. Quantitative response of a pGESS-Tc.

Fig. S3. Colony forming units (CFU) of pGESS-DAAT.

Fig. S4. Two-step protocol-based metagenome screening.

Table S1. Primer list 
(A)

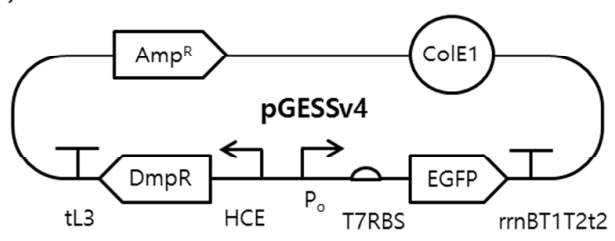

(B)

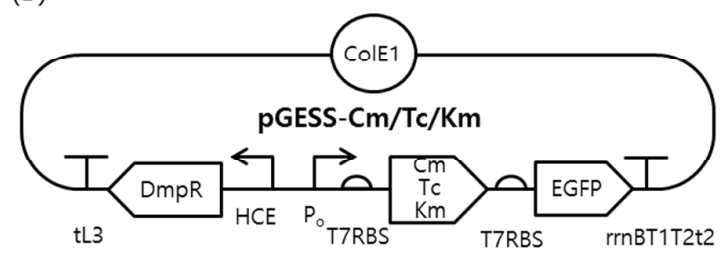

(C)

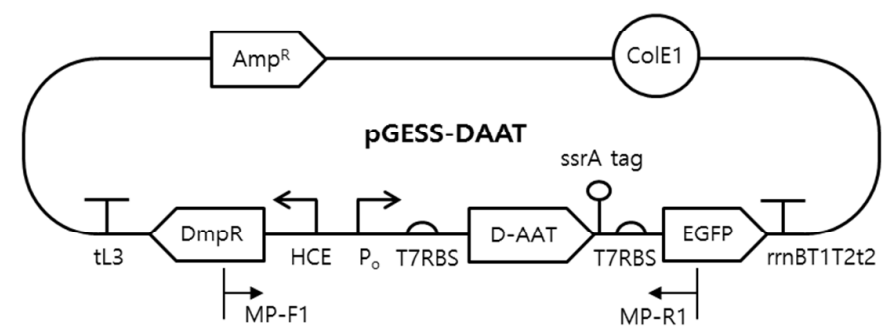

(D)

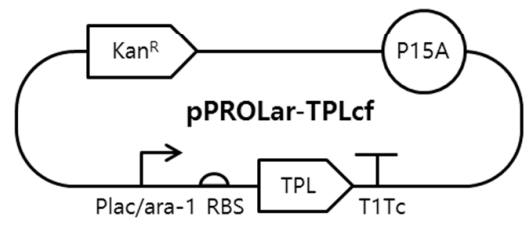

4 Figure S1. Vector maps for MP-GESS construction and evaluation. (A) pGESSv4, (B)

5 pGESS-Cm/Tc/Km, (C) pGESS-DAAT, and (D) pPROLar-TPLcf. 
Phenol

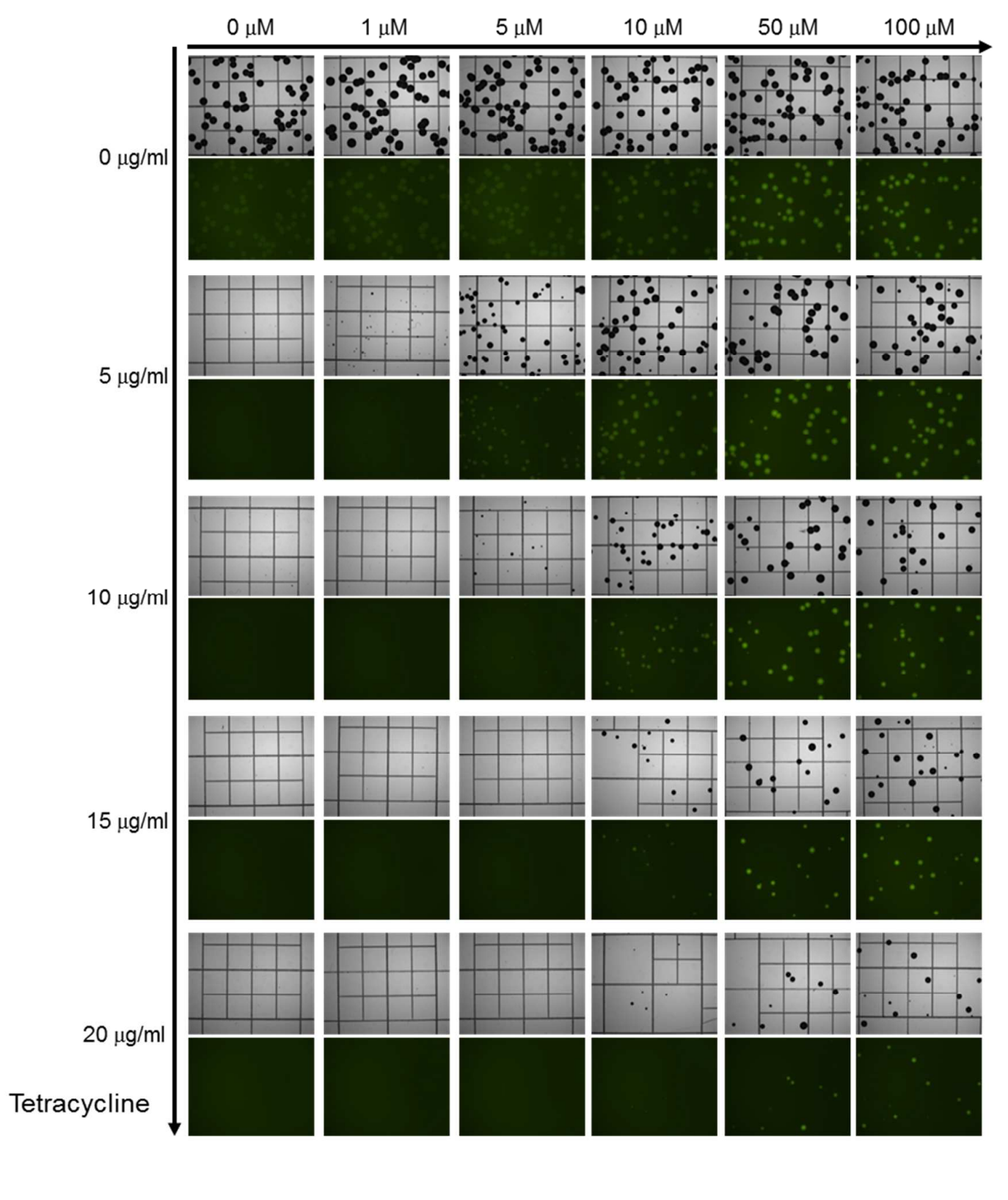

3 Figure S2. Quantitative response of a pGESS-Tc. pGESS-Tc was transformed into DH5 $\alpha$

4 cells, and a single colony was inoculated into $1 \mathrm{~mL} \mathrm{LB}$ medium with $10 \mathrm{mM}$ tetracycline

5 overnight. Then, $2 \times 10^{2}$ cells were spread on a 9-mm plate with appropriate concentrations

6 of tetracycline and phenol. As the phenol concentration increased, the number of colonies and

7 fluorescence intensity quantitatively increased at all tetracycline concentrations. 


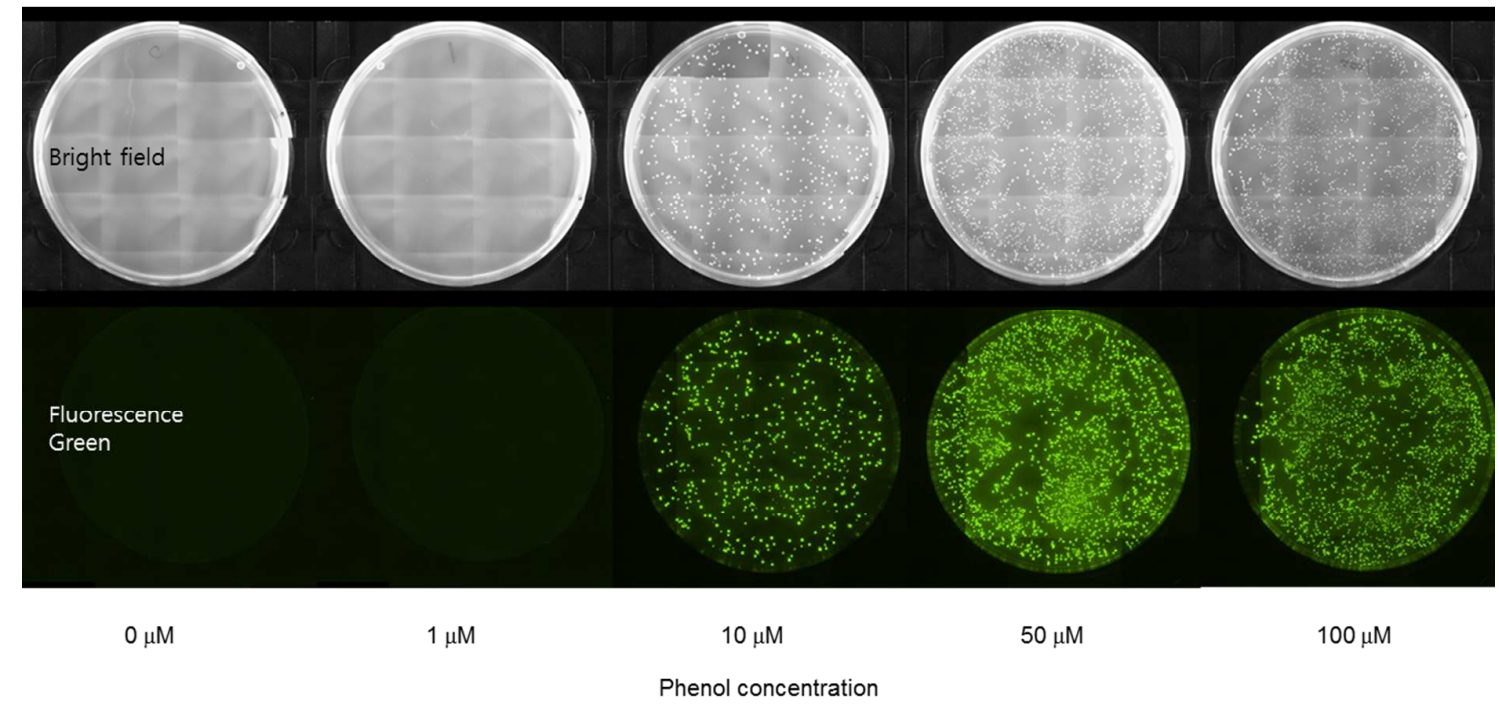

3

4 Figure S3. Colony forming units (CFU) of pGESS-DAAT. As the phenol concentration 5 increased, the number of colonies and fluorescence intensity quantitatively increased. 6 


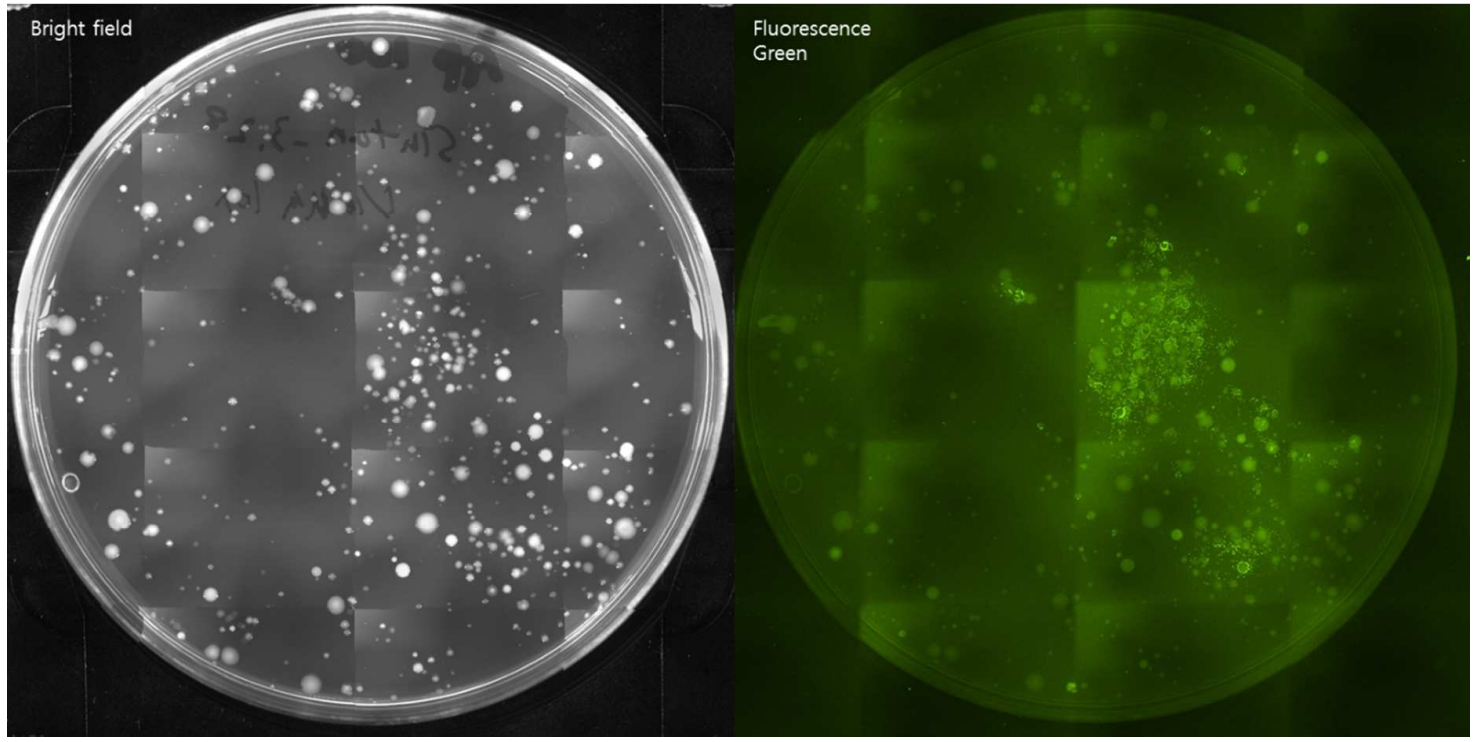

3

4 Figure S4. Cell-cell communication based metagenome screening. Sensor cells

5 clearly highlighted the candidate microorganisms with phosphatase activity from a soil

6 sample. 
2 Table S1. Primer list

\begin{tabular}{|c|c|c|}
\hline No. & Reference & Strain \\
\hline Vector-F1 & aaggagatatacatatggtgagcaagggcg & $\begin{array}{l}\text { For the amplification of pGESSv4 including RBS 14bp and } \\
\text { EGFP N-terminus } 16 \mathrm{bp} \text {. }\end{array}$ \\
\hline Vector-R1 & $\underline{\text { atgtatatctccttctccaggttggcggat }}$ & $\begin{array}{l}\text { For the amplification of pGESSv4 including EGFP upstream } \\
30 \mathrm{bp} \text {. }\end{array}$ \\
\hline DAAT-N-F1 & $\underline{\text { atgttggaacaaccaataggagtcattgattc }}$ & DAAT N-terminal exact primer \\
\hline DAAT-C-R1 & $\underline{\text { tcttttaatcggttcttgcagtgagatacatt }}$ & DAAT C-terminal exact primer \\
\hline LP-DAAT-F1 & $\underline{\text { atccgccaacctggagaaggagatatacatatgttggaacaaccaataggag }}$ & $\begin{array}{l}\text { A primer having homologous region }(30 \mathrm{bp}) \text { with plasmid } \\
\text { vector. Underlined DNA letters: DAAT-N-terminus ( } 22 \mathrm{bp}) \text {. }\end{array}$ \\
\hline LP-DAAT-R1 & $\begin{array}{l}\text { CgccettgctcaccatatgtatatctccttCTAagctgctaaagcgtagttttcgtcgtt } \\
\underline{\text { tgctgctcttttaatcggtt }}\end{array}$ & $\begin{array}{l}\text { A primer having homologous region ( } 30 \mathrm{bp} \text { ) with plasmid } \\
\text { vector. Underlined DNA letters: DAAT c-terminus } 14 \mathrm{bp} \text {, } \\
\text { bold letters: ssrA tag } 30 \mathrm{bp} \text {, Capital letters: stop codon. }\end{array}$ \\
\hline MP-F1 & Tgaaacctgcagcaacagcatgcgttgttc & A primer for colony $\mathrm{PCR}$ \\
\hline MP-R1 & ggtgaacagctcctcgecettgetcaccat & A primer for colony $\mathrm{PCR}$ \\
\hline
\end{tabular}

3 